\title{
HLA-DR and -DQ phenotypes in inflammatory bowel disease: a meta-analysis
}

\author{
P C F Stokkers, P H Reitsma, G N J Tytgat, S J H van Deventer
}

\begin{abstract}
Background-Susceptibility to inflammatory bowel disease (IBD) is partially genetically determined and the HLA class II genes are candidates for a role in genetic susceptibility to IBD, because their products play a central role in the immune response. Multiple studies have reported associations between HLA-DR or -DQ phenotypes and either ulcerative colitis or Crohn's disease, but much of the data are still controversial.

Aims-To estimate overall associations between HLA class II phenotypes and IBD, and to establish the relative risk conferred by HLA-DR and -DQ phenotypes by meta-analysis.

Methods-Medline was searched for publications reporting on the relation between IBD and HLA class II phenotypes. Raw data were extracted by recalculating the number of phenotypes or the number of alleles of the main antigens. Odds ratios and confidence intervals were calculated according to the Mantel-Haenszel method.

Results-DR2, DR9, and DRB1*0103 were positively associated with ulcerative colitis, and a negative association was found for DR4 and ulcerative colitis. For Crohn's disease a positive association was found with DR7, DRB3*0301, and DQ4 and a negative association with DR2 and DR3. Conclusions-Both ulcerative colitis and Crohn's disease are associated with specific HLA class II phenotypes. Further analysis of these phenotypes and subgroup analysis may elucidate how these alleles contribute to susceptibility to IBD.

(Gut 1999;45:395-401)
\end{abstract}

Keywords: ulcerative colitis; Crohn's disease; HLA-DR; HLA-DQ

Laboratory for Experimental Internal Medicine, Academic Medical Centre, G2-105, Meibergdreef 9, $1105 \mathrm{AZ}$ Amsterdam, The

Netherlands

P C F Stokkers

P H Reitsma

G N J Tytgat

S J H van Deventer

Correspondence to: Dr Stokkers.

Accepted for publication 5 March 1999
Susceptibility to inflammatory bowel disease (IBD) is partially genetically determined. Putative associations of IBD with the polymorphic genes that are located in the major histocompatibility complex (MHC) on the short arm of chromosome 6 , have been the leucocyte antigen (HLA) class II genes are candidates for a role in the pathogenesis of IBD, because their products play a central role in the immune response.

The class II molecules consist of an $\alpha$ chain and a $\beta$ chain that form a groove in which the antigenic peptide, after partial digestion of antigen by antigen presenting cells, is conferred subject of intensive research. ${ }^{12}$ The human to the $\mathrm{T}$ cell receptor. ${ }^{3}{ }^{4}$ The three different HLA class II molecules are HLA-DP, -DQ, and -DR. Subunits of HLA-DP and -DQ are each encoded by polymorphic $\alpha$ and $\beta$ chain genes. In the case of HLA-DR there is a non-polymorphic $\alpha$ chain gene and up to three distinct highly polymorphic $\beta$ chain genes. One of these $\beta$ chain genes, $\mathrm{B} 1$, is always present in all individuals and is by far the most polymorphic. Therefore, molecular and serological analysis of B1 chain polymorphisms has become an important tool in studies of the relation between HLA class II genes and disease.

Generally, patients and controls are typed for the main serological antigens, HLA-DR1-10, although the main antigens can be further subspecified. The alleles are grouped by the serological phenotypic characteristics they share. Serological typing has become more specific and subclasses have been identified. Split antigens for DR2, DR3, DR5, and DR6 are DR1 5 and 16, DR1 7 and 18,DR11 and 12, and DR13 and 14 respectively. DQ1 was split into DQ5 and 6, DQ3 into DQ7-9. Molecular typing of HLA alleles distinguishes even more subclasses and is more reliable than serotyping. Therefore, molecular typing is generally preferred and current HLA nomenclature is based on this method. The names summarise the name of the molecule, the chain, the gene number by which it is encoded, an asterisk as an indication of molecular typing, and the number of the allele. Thus HLA-DRB $1^{\star} 0401$ denotes an allele on the first gene defining a $\beta$ chain for the HLA-DR molecule (fig 1).

Besides the fact that the alleles can be used to study the relation between HLA class II genes and disease, polymorphic sequences may have functional implications. Different alleles have different peptide binding characteristics, and polymorphisms that are located outside the binding site of the molecules may affect interaction with $\mathrm{T}$ cells or expression of the HLA molecule. ${ }^{5}$ However, association between an HLA allele and disease does not prove such a functional relation. The MHC region contains numerous immune related genes, and it has now become clear that the different alleles of the MHC genes are strongly linked. For example, HLA-DR3 is in linkage disequilibrium with HLA-A1, B8, and the infrequent allele of a polymorphism in the tumour necrosis factor (TNF) promoter region (TNF-308).

Abbreviations used in this paper: $\mathrm{CI}$, confidence interval; HLA, human leucocyte antigen; IBD, inflammatory bowel disease; MHC, major histocompatibility complex; OR, odds ratio; TNF, tumour necrosis factor. 
Chromosome 6

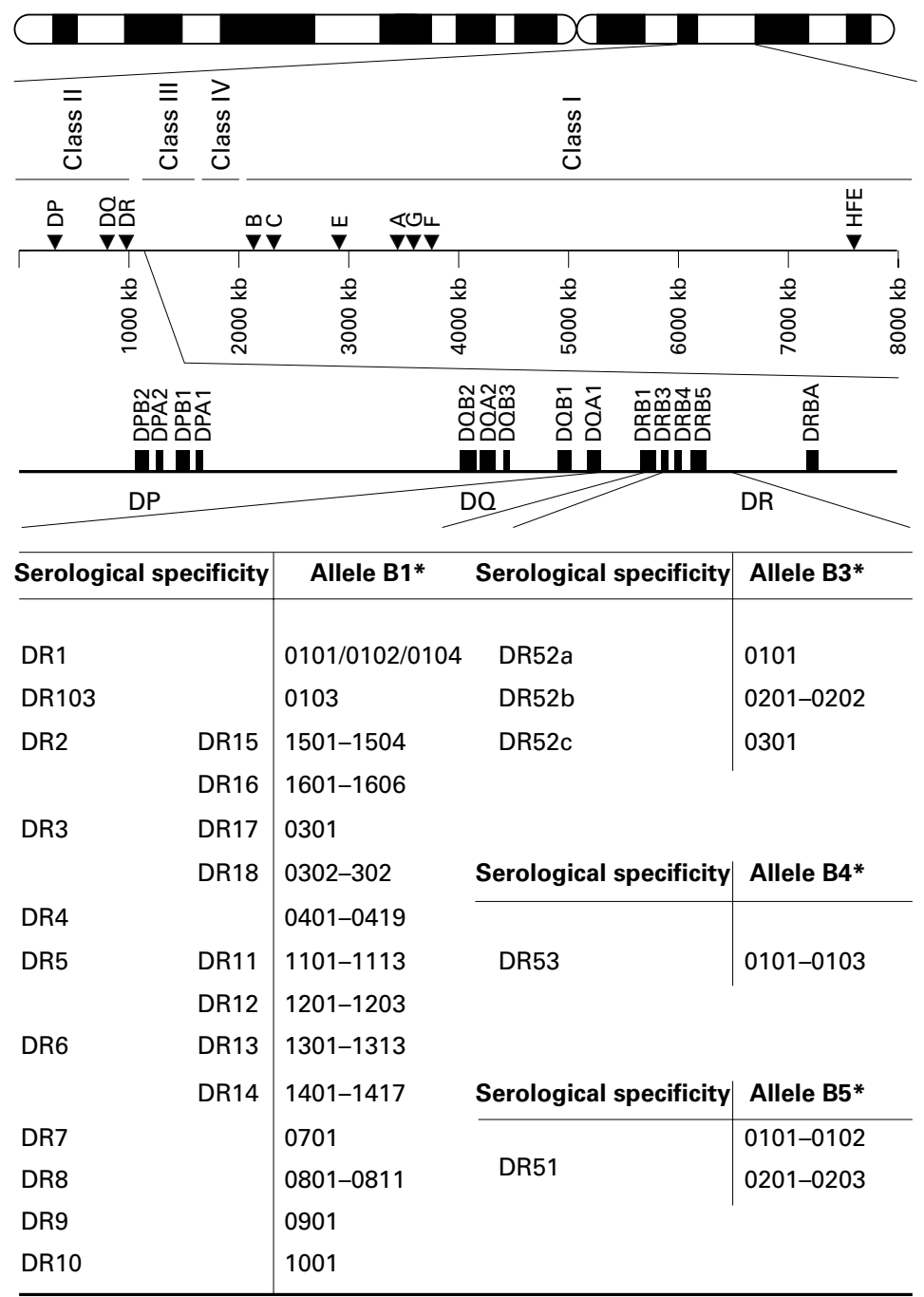

Figure 1 HLA-DR gene nomenclature. The HLA-DR genes are located in the major histocompatibility region on chromosome 6. The DRA gene, encoding the a chain of the molecule is not polymorphic. The DRB 1, 3, 4, and 5 genes are polymorphic. The serological specificities of the DRB1,DRB3,DRB4, and DRB5 polymorphisms and the corresponding genotypes are shown.
DQB $1{ }^{\star} 0201,{ }^{26}$ and negative associations with DQ $1^{10}$ and DQ $6^{25}$ have been reported.

Association studies are prone to false positive results, in particular when small groups are tested and when inadequate racial matching exists between controls and patients. Therefore, we have performed a meta-analysis of the literature. The aim of our study was to calculate overall associations between HLA-DR alleles and IBD.

\section{Material and methods}

Publications reporting the HLA-DR or -DQ main antigen frequency in healthy controls compared with either ulcerative colitis, Crohn's disease, or both were identified by searching Medline for the years 1966 to June 1998. The keywords used were: inflammatory bowel disease, Crohn's disease, ulcerative colitis, and regional enteritis, separately and in combination with HLA. A book chapter on genetics and $\mathrm{IBD}^{2}$ and the reference lists of the papers found were also used as a source. Studies that exclusively addressed the relation of HLA-DR/DQ antigens in disease subgroups defined by clinical criteria or other disease markers were not included. Studies on subspecificities were only included when the frequency of the main antigen could be extracted and reports on haplotype frequencies were excluded from the analysis. Full information on the phenotype frequency of at least one of the main antigens was sufficient for inclusion in the metaanalysis. When necessary, authors were contacted for additional information.

In order to compare studies that used serological typing and genotyping, we used the following rules:

- Data on the frequency of DR17 were included in the analysis of DR3 although this ignores the existence of the rare DR18 alleles.

- Some studies reported DR2 frequencies, whereas others reported DR15 and DR16 frequencies. In the latter situation, we summed the given value of both antigens, ignoring the possibility of DR15/DR16 heterozygotes. The data on DR6 and the DR13/14 split antigens were analysed similarly. For DQ1 and its split antigens DQ5/DQ6 we considered this approach unsuitable, because DQ5 and DQ6 heterozygotes are frequent.

- Studies on both phenotype frequencies and allele frequencies were included.

The analysis required knowledge of either the number of individuals or the number of alleles. Therefore, when only percentages were given, we recalculated the original number of patients, rounding the numbers according to conventional rules. For two studies on Crohn's disease odds ratios were calculated from allele frequencies instead of phenotype frequencies. ${ }^{711}$ All other studies reported phenotype frequencies or both. In these cases odds ratios were calculated from the phenotype frequencies.

One study mentioned allele frequencies while the data indicated that phenotype frequencies were given because the percentages negatively with DQ3. ${ }^{17}$ Higher frequencies of DQ4 have been found in patients with Crohn's disease in three studies. ${ }^{9}{ }^{1125}$ In addition, positive associations with $\mathrm{DQ} 3^{10}$ and 
Table 1 Studies included in the meta-analysis, number of subjects, and ethnic background

\begin{tabular}{|c|c|c|c|c|c|c|}
\hline \multicolumn{3}{|c|}{ Study } & \multicolumn{2}{|c|}{ Patients } & \multirow[b]{2}{*}{ Controls } & \multirow[b]{2}{*}{ Population } \\
\hline No & First author & Year & $U C$ & $C D$ & & \\
\hline 1 & Peña ${ }^{48}$ & 1980 & - & 65 & 48 & Dutch \\
\hline 2 & Asakura $^{18}$ & 1982 & 40 & - & 51 & Japanese \\
\hline 3 & Smolen ${ }^{31}$ & 1982 & 30 & 27 & 25 & Middle European \\
\hline 4 & McConnell ${ }^{23}$ & 1983 & 31 & - & 149 & British \\
\hline 5 & Caruso $^{12}$ & 1983 & - & 28 & 132 & Sicilian \\
\hline 6 & Fujita $^{8}$ & 1984 & - & 27 & 231 & Japanese \\
\hline 7 & Cottone $^{34}$ & 1985 & 46 & - & 169 & British \\
\hline 8 & Caruso $^{19}$ & 1985 & 41 & - & 151 & Sicilian \\
\hline 9 & Kobayashi $^{16}$ & 1990 & - & 30 & 54 & Japanese \\
\hline 10 & Kobayashi $^{10}$ & 1990 & 26 & - & 54 & Japanese \\
\hline 11 & Purrmann $^{14}$ & 1990 & 296 & & 300 & German, white \\
\hline 12 & Matake $^{9}$ & 1992 & - & 149 & 136 & Japanese \\
\hline 13 & Zetterquist $^{37}$ & 1992 & 89 & 65 & 250 & Swedish, white \\
\hline 14 & Toyoda $^{6}$ & 1993 & 26 & 74 & 77 & American \\
\hline 15 & Sugimura $^{17}$ & 1993 & 37 & - & 99 & Japanese \\
\hline 16 & Wassmuth $^{24}$ & 1993 & - & 109 & 85 & Swedish \\
\hline 17 & Mehal $^{32}$ & 1994 & 42 & - & 64 & British, white \\
\hline 18 & Futami $^{30}$ & 1995 & 59 & - & 150 & Japanese \\
\hline 19 & Leidenius $^{21}$ & 1995 & 77 & - & 106 & Finnish \\
\hline 20 & Duerr $^{33}$ & 1995 & 97 & - & 149 & $\begin{array}{l}\text { North American, } \\
\text { Jewish/non-Jewish }\end{array}$ \\
\hline 21 & Nakajima $^{25}$ & 1995 & - & 90 & 336 & Japanese \\
\hline 22 & Danze $^{7}$ & 1996 & - & 344 & 488 & French, white \\
\hline 23 & Satsangi $^{22}$ & 1996 & 175 & 173 & 472 & British, white \\
\hline 24 & Forcione $^{13}$ & 1996 & 40 & $42^{\star}$ & 93 & North American, white \\
\hline 25 & Reinshagen $^{11}$ & 1996 & - & 162 & 4251 & German, white \\
\hline 26 & De la Concha ${ }^{20}$ & 1997 & 107 & - & 200 & Spanish, white \\
\hline 27 & Bouma $^{15}$ & 1997 & 59 & 89 & 2400 & Dutch, white \\
\hline 28 & Cariappa $^{26}$ & 1998 & - & 58 & 93 & North American, white \\
\hline 29 & Stokkers & & 70 & 69 & 420 & Dutch, white \\
\hline
\end{tabular}

«Not used because the data on Crohn's disease (CD) are included in study 28.

UC, ulcerative colitis.

of the healthy controls were similar to the phenotype frequencies found in other studies. ${ }^{22}$ Furthermore, summing the percentages yielded a total which exceeded $100 \%$, implying that phenotype frequencies were given. Therefore, we handled these data as phenotype frequencies. Another study analysed the data in relation to two different control groups, one group of healthy individuals from the same island as the patients (Kyushu Island) and a group from the general Japanese population, and we decided to include the first control group. ${ }^{9}$ One study ${ }^{26}$ presented data on patients with Crohn's disease from an earlier study, ${ }^{13}$ including additional patients with Crohn's disease and providing more detailed typing. The data from the follow up study were included in the meta-analysis. Finally, one study ${ }^{27}$ presented data that had been included in another study, which combined data from different

Table 2 Combined analysis of HLA-DR antigens in relation to inflammatory bowel disease

\begin{tabular}{|c|c|c|c|c|c|}
\hline \multicolumn{2}{|c|}{$H L A-D R$ antigen } & \multicolumn{2}{|c|}{ Number of studies } & \multicolumn{2}{|l|}{ OR $(95 \% C I)$} \\
\hline Main & Split & $C D$ & $U C$ & $C D$ & $U C$ \\
\hline$\overline{\mathrm{DR} 1}$ & & 14 & 13 & $0.90(0.64-1.26)$ & $1.08(0.81-1.44)$ \\
\hline \multirow[t]{3}{*}{ DR2 } & & 15 & 17 & $0.83(0.70-0.98)$ & $2.00(1.52-2.63)$ \\
\hline & DR15 & 4 & 6 & $1.13(0.91-1.40)$ & $1.65(1.22-2.25)$ \\
\hline & DR16 & 4 & 6 & $0.67(0.30-1.51)$ & $0.59(0.30-1.23)$ \\
\hline DR3 & & 12 & 13 & $0.71(0.56-0.90)$ & $0.83(0.63-1.09)$ \\
\hline DR4 & & 15 & 15 & $1.18(0.89-1.56)$ & $0.54(0.43-0.68)$ \\
\hline \multirow[t]{3}{*}{ DR5 } & & 14 & 14 & $1.18(0.99-1.42)$ & $1.22(0.93-1.60)$ \\
\hline & DR11 & 6 & 4 & $1.03(0.82-1.29)$ & $1.09(0.66-1.80)$ \\
\hline & DR12 & 6 & 4 & $1.15(0.75-1.77)$ & $1.06(0.30-4.12)$ \\
\hline \multirow[t]{3}{*}{ DR6 } & & 14 & 12 & $1.07(0.89-1.27)$ & $0.82(0.60-1.12)$ \\
\hline & DR13 & 6 & 5 & $1.23(0.99-1.51)$ & $0.82(0.52-1.29)$ \\
\hline & DR14 & 6 & 5 & $0.79(0.48-1.30)$ & $0.95(0.56-1.63)$ \\
\hline DR7 & & 12 & 11 & $1.42(1.16-1.74)$ & $0.87(0.66-1.14)$ \\
\hline DR8 & & 14 & 11 & $1.11(0.82-1.49)$ & $1.03(0.72-1.47)$ \\
\hline DR9 & & 12 & 12 & $1.12(0.63-1.98)$ & $1.54(1.06-2.24)$ \\
\hline DR10 & & 9 & 8 & $1.65(0.91-2.98)$ & $0.55(0.23-1.30)$ \\
\hline DR103 & & & 3 & $3.42(1.52-7.69)$ & \\
\hline
\end{tabular}

CD, Crohn's disease; UC, ulcerative colitis; OR, odds ratio; CI, confidence interval. groups (G Semana, personal communication). ${ }^{7}$ Therefore, the study by Heresbach and colleagues $^{27}$ was excluded from the analysis.

STATISTICS

Odds ratios (OR) and 95\% confidence intervals (CI) were determined by the DerSimonian and Laird method using Review Manager version 3.1 software (Update Software Ltd, Oxford, UK). Analysis was done using a random effect model. The aetiological fraction and preventive fraction, which estimate the relative contribution of a marker to the disease susceptibility or prevention, were calculated as described previously. ${ }^{28}$

\section{Results}

The literature search yielded 29 studies that reported on studies containing information on HLA-DR/DQ phenotype or allele frequencies in IBD patients compared with healthy controls. Table 1 lists the number of patients in each study and their ethnic background.

Fifteen studies on Crohn's disease and HLA-DR antigens were included in the analysis; table 2 lists the results. A negative association was found for DR2 $(\mathrm{OR}=0.83, \mathrm{CI}$ $=0.70-0.98)($ fig $2 \mathrm{~A})$ and $\mathrm{DR} 3(\mathrm{OR}=0.71, \mathrm{CI}$ $=0.56-0.90$ ) (fig $2 \mathrm{~B}$ ) yielding preventive fractions of 0.04 and 0.04 respectively. HLA-DR7 (fig 2C) seemed to be associated with disease $(\mathrm{OR}=1.42, \mathrm{CI}=1.16-1.74)$ as was DQ4 (OR $=1.88, \mathrm{CI}=1.16-3.05$ ) (fig $2 \mathrm{D}$ ), resulting in an aetiological fraction of 0.06 and 0.04 respectively. Three studies reported on allele DRB ${ }^{\star} 0301$ and meta-analysis resulted in a positive association of this allele with Crohn's disease $(\mathrm{OR}=2.18, \mathrm{CI}=1.25-3.80$, aetiological fraction $=0.11)($ fig $2 \mathrm{E})$. 
A

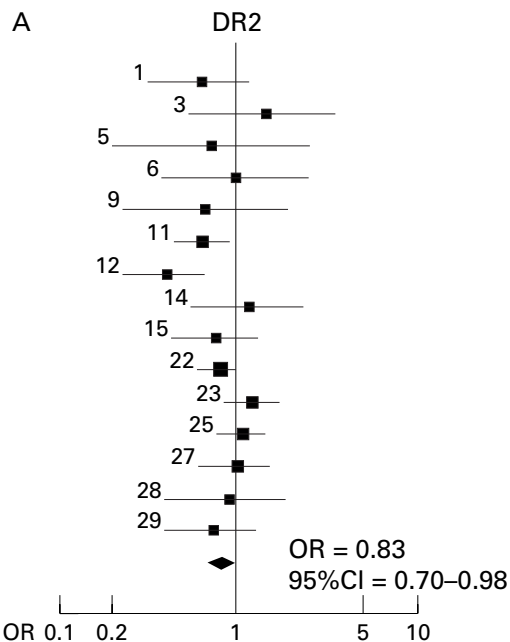

B

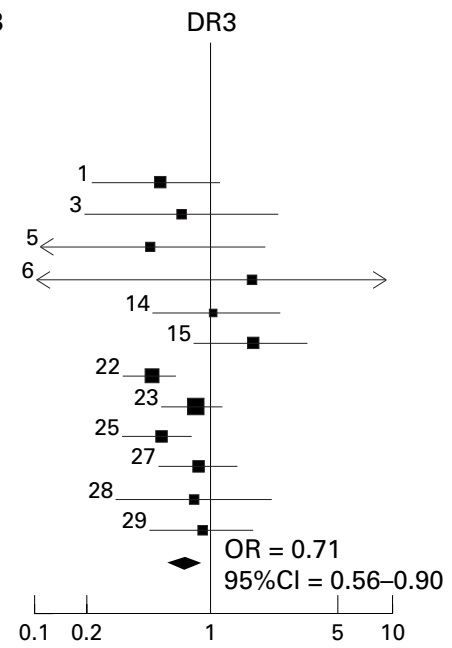

C

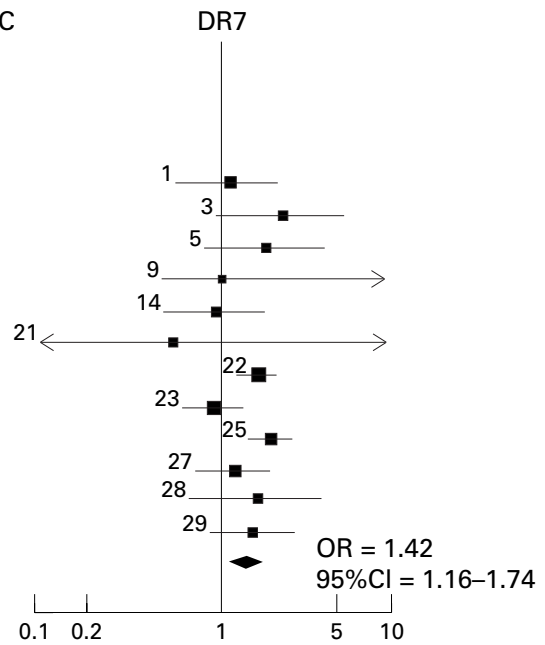

D

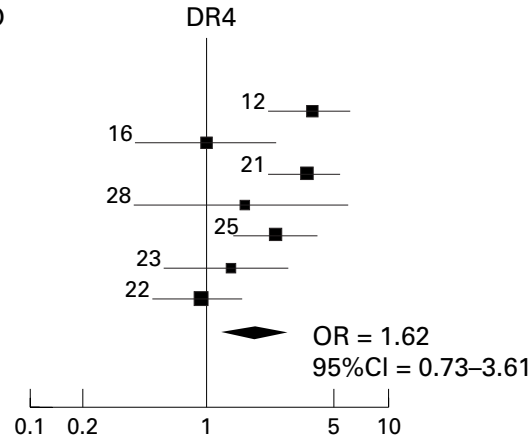

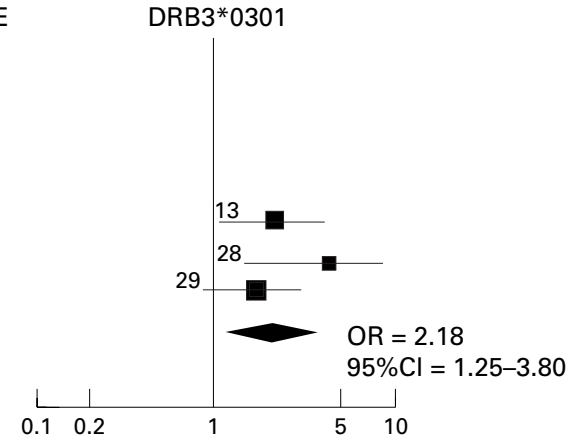

Figure 2 Associations between HLA-DR/DO phenotypes and Crohn's disease. The odds ratio is on the $x$ axis. The odds ratios of the individual studies are indicated by the squares, the size indicates the weight of the studies in the meta-analysis, and the lines reflect the confidence intervals. The numbers refer to the study numbers listed in table 1. The diamond depicts the overall odds ratio and confidence interval. (A) HLA-DR2; (B) HLA-DR3; (C) HLA-DR7;

(D) $H L A-D Q 4 ;$ (E) $H L A-D R B 3{ }^{*} 0301$.
Table 3 Combined analysis of HLA-DQ antigens in relation to inflammatory bowel disease

\begin{tabular}{|c|c|c|c|c|c|}
\hline \multicolumn{2}{|c|}{$H L A-D Q$ antigen } & \multicolumn{2}{|c|}{ Number of studies } & \multicolumn{2}{|l|}{ OR $(95 \% C I)$} \\
\hline Main & Split & $C D$ & $U C$ & $C D$ & $U C$ \\
\hline \multirow[t]{3}{*}{ DQ1 } & & 3 & 1 & $0.63(0.36-1.08)$ & ND \\
\hline & DQ5 & 6 & 2 & $1.02(0.79-1.36)$ & $1.30(0.94-1.80)$ \\
\hline & DQ6 & 6 & 2 & $0.83(0.61-1.12)$ & $1.16(0.61-1.12)$ \\
\hline DQ2 & & 4 & 3 & $1.14(0.73-1.78)$ & $0.45(0.45-1.10)$ \\
\hline \multirow[t]{4}{*}{ DQ3 } & & 2 & 1 & $1.65(0.29-9.57)$ & ND \\
\hline & DQ7 & 3 & 2 & $0.99(0.75-1.31)$ & $0.93(0.67-1.28)$ \\
\hline & DQ8 & 7 & - & $0.90(0.71-1.14)$ & ND \\
\hline & DQ9 & 6 & - & $0.98(0.70-1.36)$ & ND \\
\hline DQ4 & & 7 & 1 & $1.88(1.16-3.05)$ & ND \\
\hline
\end{tabular}

CD, Crohn's disease; UC, ulcerative colitis; OR, odds ratio; CI, confidence interval.

Eighteen studies qualified for the analysis of ulcerative colitis in relation to one or more main antigens; table 2 lists the results. The repeatedly observed association with HLADR2 was confirmed in the cumulative odds ratio: $\mathrm{OR}=2.00, \mathrm{CI}=1.5-2.63$ and aetiological fraction $=0.20$ (fig 3A). The split antigen DR15 yielded somewhat lower values $(\mathrm{OR}=$ $1.65, \mathrm{CI}=1.22-2.25)$, whereas no association was found with DR16 (table 2). Analysis of the DR15 subspecificities showed a significant association with $\mathrm{DRB} 1{ }^{\star} 1502$, but not with the other alleles (table 3, fig 3D-E). An overall lower frequency was found for the DR4 antigen $(\mathrm{OR}=0.54, \mathrm{CI}=0.43-0.68$, preventive fraction $=0.15$ ) (fig 3B). Surprisingly, an association with DR9 was found for ulcerative colitis: $\mathrm{OR}=1.54, \mathrm{CI}=1.06-2.24$ and aetiological fraction 0.03 (fig 3C). Three studies reported on allele DRB $1^{\star} 0103$ and metaanalysis resulted in a positive association of this allele with ulcerative colitis $(\mathrm{OR}=3.42$, $\mathrm{CI}=1.52-3.69$, aetiological fraction $=0.05$ ) (fig $3 \mathrm{~F}$ ).

Four studies on ulcerative colitis and nine studies on Crohn's disease and DQ antigens were included in the meta-analysis. Metaanalysis showed a positive association between DQ4 and Crohn's disease $(\mathrm{OR}=1.88, \mathrm{CI}=$ 1.16-3.05). No other associations were established.

\section{Discussion}

Our meta-analysis confirmed a positive association of ulcerative colitis with DR2 and allele 1502 of its split antigen DR15. Interestingly, an association between HLA-DR9 and ulcerative colitis was also found. In addition, HLA-DR4 seemed to be protective against ulcerative colitis. HLA-DR7, DRB3 ${ }^{\star} 0301$ and DQ4 were positively associated with Crohn's disease, and negative associations with DR2 and DR3 were noted.

In order to maximally extract information on HLA-disease associations, several concessions were made. Summing the number of patients that are DR15 and $16, \mathrm{DR} 11$ and 12 , and DR13 and 14 positive does not necessarily 
A

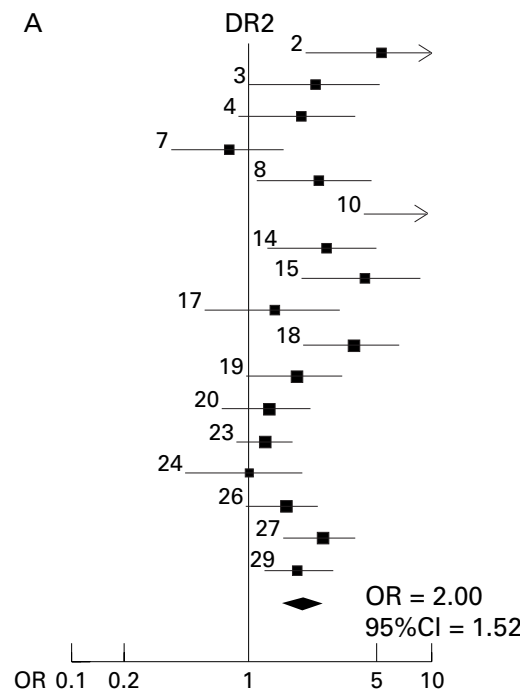

B

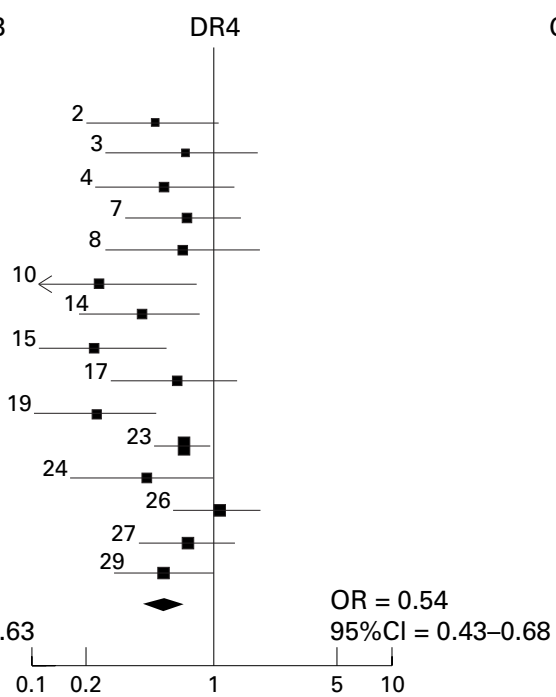

D
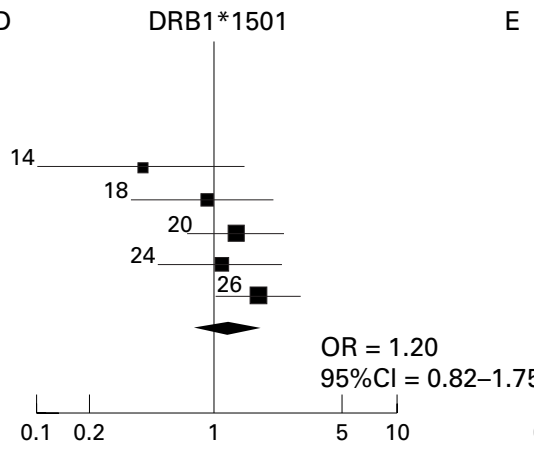

$\mathrm{E}$

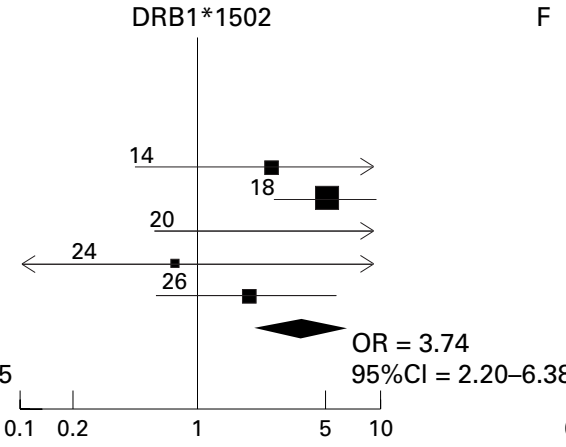

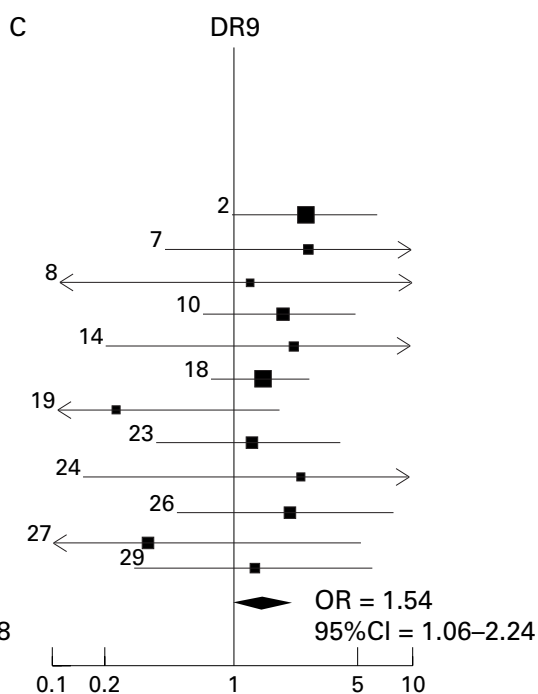

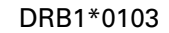

Figure $3 H L A-D R / D O$ phenotypes and ulcerative colitis. The odds ratio is on the $x$ axis. The odds ratios of the individual studies are indicated by the squares, the size indicates the weight of the studies in the meta-analysis, and the lines reflect the confidence intervals. The numbers refer to the study numbers listed in table 1. The diamond depicts the overall odds ratio and confidence interval. (A) HLA-DR2; (B) HLA-DR4; (C) HLA-DR9; (D) $H L A-D R B 11^{\star} 1501$; (E) HLA-DRB1*1502; (F) HLA-DRB1*0103.

yield the number of DR2, DR5, and DR6 positives respectively. If many individuals were heterozygous for these split antigens it could lead to an overestimation of DR2, DR5, or DR6. Because DR12 and DR16 are rare, this would have only a minor effect on the outcome of our analysis. DR13 and DR14 are more frequent and therefore their combined incidence may be greater than the real DR6 phenotype frequency. However, omitting the studies in which we summed DR13 and DR14 positives did not yield an overall association with DR6 (data not shown).

Another potential confounder of metaanalyses is disease heterogeneity. Ulcerative colitis and Crohn's disease may not encompass defined diseases but represent rather heterogenic disorders with different genetic backgrounds. In this case, in one population a certain HLA-DR allele could confer disease susceptibility, whereas in another population other genes may play a role. Hence, when overall associations are found in a meta-analysis that includes studies with different ethnic, racial, and geographical factors, a strong argument for a transethnic analysis of these phenotypes in relation to disease subgroups is provided. Moreover, when Japanese studies and studies on white populations were analysed separately, no gross differences in the outcome were observed.

The association of $\mathrm{DR} 2^{15}$ with ulcerative colitis was frequently noted in the homogeneous Japanese population. ${ }^{16-18}{ }^{30}$ In other homogeneous populations such as the Sicilians ${ }^{19}$ and the Finns, ${ }^{21}$ increased frequencies were also found. However, studies in more heterogeneous white populations gave conflicting results. Some studies confirmed the increased frequency, ${ }^{6} 1520233132$ whereas others only found equal frequencies ${ }^{1322} 33$ or even a lower frequency. ${ }^{34}$ In the meta-analysis, DR2 is firmly associated with ulcerative colitis and when the Japanese studies are left out of the metaanalysis the association remains significant $(\mathrm{OR}=1.51, \mathrm{CI}=1.20-1.90$, table 4$)$. It has been suggested that the DR2 association was mainly determined by a subspecificity of $\mathrm{DR} 15, \mathrm{DRB}{ }^{\star} 1502$ which is frequently found among the Japanese. ${ }^{30}$ However, a subsequent study in whites showed that the frequencies of both subspecificities of DR15, DRB $1{ }^{\star} 1501$ and DRB1 $1^{\star} 1502$, were increased in patients with ulcerative colitis when compared with controls. ${ }^{20}$ Five studies have looked at these subspecificities and our meta-analysis shows a positive association for DRB $1{ }^{\star} 1502$ but not for $\mathrm{DRB} 1{ }^{\star} 1501$ (fig $3 \mathrm{D}-\mathrm{E}$ ). However, this result is biased by the high frequency of this allele in the 
Table 4 Associated phenotypes in Fapanese and white populations analysed separately

\begin{tabular}{|c|c|c|c|c|c|}
\hline \multirow[b]{2}{*}{$H L A-$} & \multirow[b]{2}{*}{ Disease } & \multicolumn{2}{|c|}{ Fapanese } & \multicolumn{2}{|c|}{ Whites } \\
\hline & & No & OR $(95 \% C I)$ & No & OR $(95 \% C I)$ \\
\hline \multirow[t]{2}{*}{$\overline{\mathrm{DR} 2}$} & $\mathrm{CD}$ & 3 & $0.56(0.32-0.97)$ & 11 & $0.89(0.77-1.03)$ \\
\hline & $\mathrm{UC}$ & 4 & $4.92(3.05-7.95)$ & 11 & $1.51(1.20-1.90)$ \\
\hline DR3 & $\mathrm{CD}$ & 1 & NA & 10 & $0.70(0.55-0.91)$ \\
\hline DR7 & $\mathrm{CD}$ & 2 & $2.18(0.13-37.44)$ & 9 & $1.40(1.12-1.75)$ \\
\hline DR9 & UC & 3 & $1.72(1.07-2.77)$ & 7 & $1.50(0.78-2.88)$ \\
\hline DQ4 & $\mathrm{CD}$ & 2 & $3.47(2.46-4.91)$ & 4 & $1.33(0.94-1.87)$ \\
\hline
\end{tabular}

CD, Crohn's disease; UC, ulcerative colitis; OR, odds ratio; CI, confidence interval.

Japanese study included in this analysis and the association is no longer positive when the Japanese study is omitted from the meta-analysis (data not shown). Taken together, these data suggest that in white populations, alleles other than 1502 are responsible for the association of DR2 with ulcerative colitis.

Several studies have indicated that HLADR4 protects against ulcerative colitis, ${ }^{6}{ }^{16-18} 21$ and this association is also apparent in the meta-analysis.

The meta-analysis found a novel association with HLA-DR9. The fact that this association was not noted before is probably a consequence of the low frequency of this antigen in most populations. Indeed, 10 of 12 studies reported an increased frequency of DR9 in patients with ulcerative colitis, but this increase failed to reach statistical significance. In the Japanese population, the frequency of HLADR9 is relatively high, and may thus be a more important factor for disease susceptibility compared with other populations. When the three Japanese studies were analysed separately an odds ratio of 1.72 was obtained (CI $=1.06-$ 2.78), which corresponds with an aetiological fraction of 0.15 .

Finally, the HLA-DRB $1^{\star} 0103$ allele is associated with ulcerative colitis. Three studies (one not yet published) have assessed the frequency of this rare allele in IBD patients and controls, and all reported a higher frequency in patients with ulcerative colitis. ${ }^{132}$ Others have found that this allele also predisposes to extensive disease..$^{35} 36$

Studies on HLA-DR frequencies in Crohn's disease have reported associations with $\mathrm{DR} 1,{ }^{67}$ DR4, ${ }^{8-10}$ and recently DR7. ${ }^{71}$ The latter studies also reported that DR3 conferred disease resistance. ${ }^{71}$ The meta-analysis confirmed only the positive association with HLA-DR7 and a negative association for HLA-DR3. It should be noted that HLA-DR7 is in linkage disequilibrium with HLA-B44 and it remains unclear whether the association with DR7 is indirectly due to this allele.

DRB $3^{\star} 0301$ has been associated with Crohn's disease ${ }^{26}$ and we have identified three studies (including one not yet published) that report on the phenotypic frequency of this allele. ${ }^{26}{ }^{37}$ Meta-analysis of these data shows a significant association between Crohn's disease and $\mathrm{B} 3{ }^{\star} 0301$. This allele is in tight linkage disequilibrium with $\mathrm{DRB} 1^{\star} 1302$ in whites. $^{38}$ Therefore the association may either be due to one of these alleles or due to another allele in linkage disequilibrium with the DRB $1^{\star} 1302$ B ${ }^{\star} 0301$ haplotype.
The negative association of DR3 with Crohn's disease is intriguing. Three studies have shown that the DR3 frequency is particularly low in patients with severe disease (as indicated by the need for azathioprine treatment), ${ }^{39}$ and in patients with perianal fistulas. ${ }^{40}$ In Crohn's disease, this association seems independent from linkage of DR3 with the infrequent allele of the -308 restriction fragment length polymorphism in the TNF- $\alpha$ promoter, because the frequency of this allele was not reduced in the patients with Crohn's disease with perianal fistulas. ${ }^{40}$

The association of Crohn's disease with DQ4 is no longer significant when the two Japanese studies are omitted from the analysis. The DQ4 phenotype is common among the Japanese and may therefore constitute a more important risk factor in this population.

The calculations of the aetiological and preventive fractions should be interpreted with caution, as the HLA-DR phenotype frequencies vary among different populations and data on the age distribution of the groups that were studied are lacking. ${ }^{28}{ }^{29}$ However, these calculations can serve as an indicator for the relative contribution of the specific HLA-DR molecules to disease susceptibility. Thus, the contribution of HLA-DR to disease susceptibility for ulcerative colitis is relatively high (aetiological fraction of 0.2 for DR2, 0.05 for DR103, and 0.03 for DR9), whereas for Crohn's disease the contribution for DR molecules is smaller (0.06 for DR7 and 0.11 for DRB $\left.3^{\star} 0301\right)$. These findings are in agreement with data from recent linkage analyses: for ulcerative colitis the attribution of the HLA region may determine most of the genetic aetiological fraction, whereas for Crohn's disease the role of the HLA region seemed limited..$^{22}$ The aetiological fractions that we found cannot account for the total genetic risk on IBD. Genome scans indicate that nonMHC genes may play a role as well. Linkage of disease susceptibility to loci on chromosomes $1,2,4,3,7,12,16^{41-43}$ has been reported, but replication of linkage has only been obtained for the loci on chromosomes 12 and $16 .^{44-47}$

The frequency of HLA class II alleles varies between different populations and selection bias may underlie some of the associations found by the meta-analysis. For example, the association with DR7 is not noted when the white and Japanese populations are analysed separately (table 4). This is not surprising because DR7 is very infrequent among the Japanese population and only two studies have assessed its frequency. Therefore, the aetiological fraction of DR7 is very low for the Japanese population (due to the low prevalence of DR7). Conversely, the DR9 association with ulcerative colitis and the DQ4 association with Crohn's disease are not detected when only white populations are included in the analysis. Most likely, this is also a consequence of the low frequency of these phenotypes in the white population.

In conclusion, this meta-analysis indicates that ulcerative colitis is associated with DR2, ${ }^{15}$ DR9, and DRB1*0103 and that DR4 confers 
protection. For Crohn's disease, an association with DR7, DRB3*0301, and DQ4 and a negative association with DR2 and DR3 were found. The contribution of HLA-DR molecules to the pathogenesis of ulcerative colitis may be threefold larger when compared with Crohn's disease. None of the aetiological fractions associated with these phenotypes can account for the total genetic contribution to disease susceptibility.

1 Duerr RH. Genetics of inflammatory bowel disease. Inflammatory Bowel Disease 1996;2:48-60.

2 Yang H, Rotter JI. Genetic aspects of idiopathic inflammatory bowel disease. In: Kirsner JB, Shorter RG, eds. Inflammatory bowel disease. Baltimore: Williams and Wilkins, 1995:301-31

3 Brown JH, Jardetzky TS, Gorga JC, et al. Three-dimensional structure of the human class II histocompatibility antigen HLAtructure of the human class II histoc

4 Jardetzky TS, Brown JH, Gorga JC, et al. Three-dimensional structure of a human class II histocompatibility molecule complexed with superantigen. Nature 1994;368:711-18.

5 Nepom GT, Erlich H. MHC class-II molecules and autoimmunity. Annu Rev Immunol 1991;9:493-525.

6 Toyoda H, Wang SJ, Yang HY, et al. Distinct associations of HLA class II genes with inflammatory bowel disease. Gastroenterology 1993;104:741-8.

7 Danze PM, Colombel JF, Jacquot S, et al. Association of HLA class II genes with susceptibility to Crohn's disease. Gut 1996;39:69-72.

8 Fujita K, Naito S, Okabe N, et al. Immunological studies in Crohn's disease. I. Association with HLA systems in the Japanese. F Clin Lab Immunol 1984;14:99-102.

9 Matake H, Okabe N, Naito S, et al. An HLA study on 149 Japanese patients with Crohn's disease. Gastroenterol Ipn 1992;27:496-501.

10 Kobayashi K, Atoh M, Yagita A, et al. Crohn's disease in the Japanese is associated with the HLA-DRw53. Exp Clin Japanese is associated with

11 Reinshagen M, Loeliger C, Kuehnl P, et al. HLA class II gene frequencies in Crohn's disease: a population based gene frequencies in Crohn's disease: a po

12 Caruso C, Oliva L, Palmeri P, et al. B cell alloantigens in Sicilian patients with Crohn's disease. Tissue Antigens 1983, 21:170-2.

13 Forcione DG, Sands B, Isselbacher KJ, et al. An increased risk of Crohn's disease in individuals who inherit the HLA class II DRB3*0301 allele. Proc Natl Acad Sci USA 1996;93:5094-8.

14 Purrmann J, Bertrams J, Knapp M, et al. Gene and haplotype frequencies of HLA antigens in 269 patients with Crohn's disease. Scand F Gastroenterol 1990;25:981-5.

15 Bouma G, Oudkerk Pool M, Crusius JB, et al. Evidence for genetic heterogeneity in inflammatory bowel disease (IBD); HLA genes in the predisposition to suffer from ulcerative colitis (UC) and Crohn's disease (CD). Clin Exp Immunol 1997;109:175-9.

16 Kobayashi K, Atoh M, Konoeda Y, et al. HLA-DR, DQ and $\mathrm{T}$ cell antigen receptor constant beta genes in Japanese patients

17 Sugimura K, Asakura H, Mizuki N, et al. Analysis of genes within the HLA region affecting susceptibility to ulcerative colitis. Hum Immunol 1993;36:112-18.

18 Asakura $\mathrm{H}$, Tsuchiya M, Aiso S, et al. Association of the human lymphocyte-DR2 antigen with Japanese ulcerative colitis. Gastroenterology 1982;82:413-18.

19 Caruso C, Palmeri P, Oliva L, et al. HLA antigens in ulcerative colitis: a study in the Sicilian population. Tissue Antigens 1985;25:47-9.

20 De La Concha EG, Fernandez-Arquero M, Santa-Cruz S, et al. Positive and negative associations of distinct HLA-DR2 subtypes with ulcerative colitis (UC). Clin Exp Immuno 1997;108:392-5.

21 Leidenius MH, Koskimies SA, Kellokumpu IH, et al. HLA antigens in ulcerative colitis and primary sclerosing cholangitis. APMIS 1995;103:519-24.

22 Satsangi J, Welsh KI, Bunce M, et al. Contribution of genes of the major histocompatibility complex to susceptibility and disease phenotype in inflammatory bowel disease. Lancet 1996;347:1212-17.

23 McConnell RB. Ulcerative colitis-genetic features. Scand $\mathcal{F}$ Gastroenterol 1983;88(suppl):14-16.

24 Wassmuth R, Eastman S, Kockum I, et al. HLA DR and DQ RFLP analysis in Crohn's disease. Eur $\mathcal{F}$ Immunogene 1993;20:429-33.
25 Nakajima A, Matsuhashi N, Kodama T, et al. HLA-linked susceptibility and resistance genes in Crohn's disease. Gastroenterology 1995;109:1462-7.

26 Cariappa A, Sands B, Forcione D, et al. Analysis of MHC class II DP, DQ and DR alleles in Crohn's disease. Gut 1998;43:210-15.

27 Heresbach D, Alizadeh M, Bretagne JF, et al. Investigation of the association of major histocompatibility complex genes, including HLA class I, class II and TAP genes, with clinical forms of Crohn's disease. Eur f Immunogenet 1996; 23:141-51.

28 Green A. The epidemiologic approach to studies of association between HLA and disease. I. The basic measures, concepts and estimation procedures. Tissue Antigens 1982; 19:245-58.

29 Green A. The epidemiologic approach to studies of association between HLA and disease. II. Estimation of absolute risks, etiologic and preventive fraction. Tissue Antigens 1982;19:259-68.

30 Futami S, Aoyama N, Honsako Y, et al. HLA-DRB1*1502 allele, subtype of DR15, is associated with susceptibility to ulcerative colitis and its progression. Dig Dis Sci 1995;40: $814-18$

31 Smolen JS, Gangl A, Polterauer P, et al. HLA antigens in inflammatory bowel disease. Gastroenterology 1982;82:34-

32 Mehal WZ, Lo YM, Wordsworth BP, et al. HLA DR4 is a marker for rapid disease progression in primary sclerosing cholangitis. Gastroenterology 1994;106:160-7.

33 Duerr RH, Neigut DA. Molecularly defined HLA-DR2 alleles in ulcerative colitis and an antineutrophil cytoplasmic antibody-positive subgroup. Gastroenterology 1995;108: $423-7$

34 Cottone $\mathrm{M}$, Bunce $\mathrm{M}$, Taylor CJ, et al. Ulcerative colitis and HLA phenotype. Gut 1985;26:952-4

35 Roussomoustakaki M, Satsangi J, Welsh K, et al. Genetic markers may predict disease behavior in patients with ulcerative colitis. Gastroenterology 1997;112:1845-53.

36 Duerr RH, Chensy LJ. Associations between HLA-DR alleles amd subsets of ulcerative colitis defined by extent of colitis [abstract]. Gastroenterology 1997;112:A963.

37 Zetterquist H, Broome U, Einarsson K, et al. HLA class II genes in primary sclerosing cholangitis and chronic inflammatory bowel disease: no HLA-DRw52a association in Swedish patients with sclerosing cholangitis. Gut 1992;33: $942-6$.

38 Gorski J, Tilanus M, Giphart M, et al. Oligonucleotide genotyping shows that alleles at the HLA-DR beta III locus of the DRw52 supertypic group segregate independently of known DR or Dw specificities. Immunogenetics 1987;25:7983.

39 Heresbach D, Colombel F, Danze PM, et al. The HLA $\mathrm{DRB} 1^{\star} 0301-\mathrm{DQB} 1{ }^{\star} 0201$ haplotype confers protection against inflammatory bowel disease. Am $\mathcal{f}$ Gastroenterol 1996;91:1060

40 Bouma G, Poen AC, Garcia-Gonzalez MA, et al. HLADRB1 ${ }^{\star} 03$, but not the TNFA-308 promoter gene polymorphism, confers protection against fistulising Crohn's disease. Immunogenetics 1998;47:451-5.

41 Hugot JP, Laurent-Puig P, Gower-Rousseau C, et al. Mapping of a susceptibility locus for Crohn's disease on chromosome 16. Nature 1996:379:821-3.

42 Cho JH, Nicolae DL, Gold LH, et al. Identification of novel susceptibility loci for inflammatory bowel disease on chromosomes 1p, 3q, and 4q: evidence for epistasis between $1 \mathrm{p}$ and IBD1. Proc Natl Acad Sci USA 1998;95:7502-7.

43 Satsangi J, Parkes M, Louis E, et al. Two stage genome-wide search in inflammatory bowel disease provides evidence for susceptibility loci on chromosomes 3, 7 and 12. Nature Genet 1996;14:199-202.

44 Curran ME, Lau KF, Hampe J, et al. Genetic analysis of inflammatory bowel disease in a large European cohort supports linkage to chromosomes 12 and 16. Gastroenterology 1998;115:1066-71.

45 Duerr RH, Barmada MM, Zhang L, et al. Linkage and association between inflammatory bowel disease and a locus on chromosome 12. Am f Hum Genet 1998;63:95100.

46 Mirza MM, Lee J, Teare D, et al. Evidence of linkage of the inflammatory bowel disease susceptibility locus on chromosome 16 (IBD1) to ulcerative colitis. F Med Genet 1998; 35:218-21.

47 Brant SR, Fu Y, Fields CT, et al. American families with Crohn's disease have strong evidence for linkage to chromosome 16 but not chromosome 12. Gastroenterology 1998;115:1056-61.

48 Pena AS, Biemond I, Kuiper G, et al. HLA antigen distribution and HLA haplotype segregation in Crohn's disease. Tissue Antigens 1980;16:56-61. 